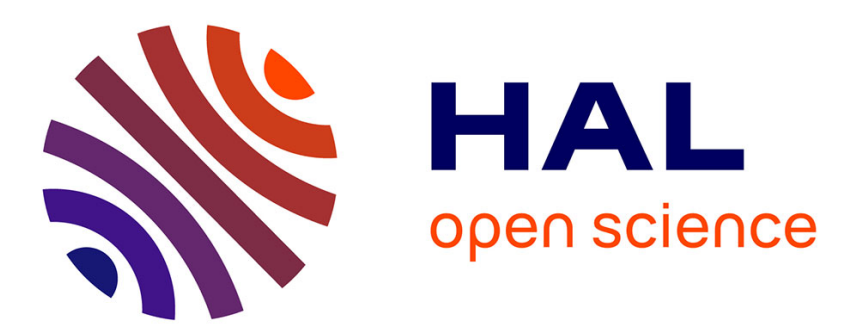

\title{
Effect of interstitial carbon distribution and nickel substitution on the tetragonality of martensite: A first-principles study
}

S. Chentouf, Sophie Cazottes, F. Danoix, M. Gouné, H. Zapolsky, Philippe Maugis

\section{To cite this version:}

S. Chentouf, Sophie Cazottes, F. Danoix, M. Gouné, H. Zapolsky, et al.. Effect of interstitial carbon distribution and nickel substitution on the tetragonality of martensite: A first-principles study. Intermetallics, 2017, 89, pp.92-99. 10.1016/j.intermet.2017.05.022 . hal-01789220

\section{HAL Id: hal-01789220 \\ https://hal.science/hal-01789220}

Submitted on 1 Jun 2018

HAL is a multi-disciplinary open access archive for the deposit and dissemination of scientific research documents, whether they are published or not. The documents may come from teaching and research institutions in France or abroad, or from public or private research centers.
L'archive ouverte pluridisciplinaire HAL, est destinée au dépôt et à la diffusion de documents scientifiques de niveau recherche, publiés ou non, émanant des établissements d'enseignement et de recherche français ou étrangers, des laboratoires publics ou privés. 


\title{
Effect of interstitial carbon distribution and nickel substitution on the tetragonality of martensite: a first-principles study.
}

\author{
S. CHENTOUF ${ }^{1}$, S. CAZOTTES ${ }^{2}$, F. DANOIX ${ }^{3}$, M. GOUNE $^{4}$, H. ZAPOLSKY ${ }^{3}$ and P. \\ MAUGIS $^{1}$ \\ ${ }^{1}$ Aix Marseille Univ, CNRS, Université de Toulon, IM2NP, Marseille, France. \\ ${ }^{2}$ Université de Lyon, INSA Lyon, MATEIS-CNRS, Lyon, France. \\ ${ }^{3}$ Groupe de Physique des Matériaux, Université de Rouen, CNRS, Rouen, France. \\ ${ }^{4}$ ICMCB-CNRS, Pessac, France. \\ Email of the corresponding author: sara.chentouf@gmail.com
}

\begin{abstract}
By using first principles calculations, the effects of carbon distribution and of 25 at. $\%$ of nickel substitution on the tetragonality of ferrous martensite have been investigated. Different carbon concentrations have been considered $\left(0 \leq \mathrm{x}_{\mathrm{c}} \leq 12.5\right.$ at.\%). All calculations were based on the Projector Augmented Wave (PAW) method of the Density Functional Theory (DFT). The Special Quasirandom Structure (SQS) method has been used to model the disordered structures of the $\mathrm{Fe}_{16} \mathrm{C}_{2 \mathrm{X}}$ and $(\mathrm{Fe}, \mathrm{Ni})_{16} \mathrm{C}_{2 \mathrm{X}}$ systems. Our calculations demonstrate that the lattice parameters $a$ and $c$ vary linearly with carbon concentration, up to the high value of $\mathrm{x}_{\mathrm{c}}=12.5 \mathrm{at} . \%$ (for $\mathrm{X}=1$ ). The nickel substitution enhances the expansion of parameter $c$ of the $\mathrm{Fe}_{16} \mathrm{C}_{2 \mathrm{X}}$ system up to $37 \%$. This trend is correlated with the shear moduli calculated for bcc-iron and the disordered Fe25at.\%Ni structure. The mixing energies of the $\mathrm{Fe}_{16} \mathrm{C}_{2 \mathrm{X}}$ and $(\mathrm{Fe}, \mathrm{Ni}){ }_{16} \mathrm{C}_{2 \mathrm{X}}$ systems indicate that the unmixing of martensite by spinodal decomposition is favoured by the nickel substitution. It is shown that carbon-carbon interactions are mostly repulsive until the distance of two bcc-iron lattice parameters.
\end{abstract}

\section{Introduction}

The relation between the lattice parameters and the carbon content of ferrous martensite has been the subject of many experimental studies in the last decades. From the review of experimental measurements, Cheng et al. [1] have established the linear dependences of the bct iron-carbon martensite $a$ and $c$ parameters as functions of the number of interstitials per iron atom, $x_{C}$ :

$$
\begin{array}{lll}
a=0.28664-(0.027 \pm 0.001) x_{C} & (\mathrm{~nm})
\end{array}
$$

From these equations, the tetragonality ratio is:

$$
c / a=1+(0.95 \pm 0.01) x_{C}
$$

where $0.28664 \mathrm{~nm}$ is the adopted lattice parameter of pure bcc-iron at $300 \mathrm{~K}$.

The above equations match well many experimental data. However, some differences in tetragonality are observed for steels having the same carbon content [2]. It was shown that these differences are related to both interstitial ordering [3-4] and alloying [2,5-6]. 
It is well accepted that tetragonality of martensite formed by quenching from high-temperature cubic face centered austenite phase is a direct consequence of carbon atoms preferential location at one of the three possible sub-lattices of octahedral interstices. In 1948, Zener [7] has used the elastic interactions to explain the temperature-dependent transition between ordered and disordered interstitial carbon distributions in martensite. Later, Khachaturyan [8] proposed a detailed description of expected strain induced ordering of solutes using the Microscopic Elasticity Theory (TEM). He demonstrated that the strongly repulsive chemical interactions and elastic interactions between carbon atoms must be taken into account in order to predict the order-disorder transition. The calculations of Khachaturyan have been recently reviewed by Udyanski [9] et al. using an ab initio EAM potential for Fe-C system and molecular dynamic simulations to estimate the chemical interactions between carbon atoms.

It was also shown that martensite tetragonality depends on substitutional content. It has been observed that freshly formed martensite steels containing $\mathrm{Mn}, \mathrm{low}-\mathrm{Ni}, \mathrm{Rh}$ and $\mathrm{Cr}$ have an abnormally low tetragonality [10,11-12]. On heating these steels from room temperature the $c$ parameter increases and the $a$ parameter decreases [13-15]. Meanwhile, abnormally high tetragonality was found in freshly formed $\mathrm{Al}$ and high-Ni martensite [2, 5]. Heating freshly formed $\mathrm{Al}$ and high-Ni martensite led to a decrease of $c$ and increase of $a$ parameters. More recently, by using ab initio calculations Al-Zoubi et al. [16] found that $\mathrm{Al}$ and $\mathrm{Ni}$ addition enhances significantly the $c / a$ ratio of ordered $\mathrm{Fe}_{16} \mathrm{C}_{1}$.

The present study was carried out to investigate (i) the effect of interstitial carbon atom content and distribution and (ii) the effect of the substitutional Ni atoms on martensite tetragonality. The variation of the $a$ and $c$ lattice parameters is investigated at different carbon contents, ranging from small to high concentrations. The typical carbon content in supersaturated ferrous martensite is about $1 \mathrm{wt.} \% \mathrm{C}$ (i.e. 4.48 at.\%). However, a martensite quenched from austenite without tempering, if held at temperatures close to room temperature, will decompose to form a modulated structure of carbon-rich and carbon-lean areas. TEM and one-dimensional tomography revealed that in Fe-Ni-C alloys the nanoscale carbon-rich modulated structure results from spinodal decomposition [17-18]. Then, the carbon content, the structure and the stability of the carbon-rich regions have been the subjects of numerous experimental studies. It was suggested that these zones consist of an ordered phase. Because of the high carbon concentration of these regions (about 11.1 at.\%), it is assumed that carbon atoms ordering in one type of octahedral site might be important. Thus, three types of long-range order distributions can be considered, from the least to the most ordered: (i) carbon randomly distributed on the three octahedral sub-lattices. That is the case of highly supersaturated ferrite noted $\alpha-\mathrm{Fe}_{16} \mathrm{C}_{2}$, (ii) carbon ordered on one octahedral sub-lattice and randomly distributed on its octahedral sites. That is the case of Zener ordered martensite noted $\alpha^{\mathrm{Z}}-\mathrm{Fe}_{16} \mathrm{C}_{2}$ and (iii) carbon ordered onto one octahedral sub-lattice with occupation of only some of its sites leading to the stoichiometric structure $\alpha^{\prime \prime}-\mathrm{Fe}_{16} \mathrm{C}_{2}$. Taylor et al. [17] have found that, for carbon compositions close to 11 at.\% and for low temperatures, the stoichiometric structure type (iii) has the lowest free energy among the three types. The partially ordered $\alpha^{\mathrm{Z}}-\mathrm{Fe}_{16} \mathrm{C}_{2}$ structure (type (ii)) would be the next most stable while the least stable would correspond to $\alpha-\mathrm{Fe}_{16} \mathrm{C}_{2}$ (type (i)). These results have been confirmed by Molecular Dynamic (MD) calculations performed by Sinclair et al [19].

In the first part of this paper, the effect of interstitial carbon content (up to $\mathrm{x}_{\mathrm{c}}=12.5$ at.\%) and ordering on the structural parameters of martensite is investigated. Besides, to get information 
about the spinodal decomposition, the mixing energies are calculated for different carbon concentrations by taking as references the stoichiometric structure $\alpha^{\prime \prime}-\mathrm{Fe}_{16} \mathrm{C}_{2}$ and pure bcc-iron. The Special Quasirandom Structure method has been applied to generate different possible carbon distributions on the octahedral sites within the bcc-iron lattice. Special attention has been paid to ordering of the structure $\alpha^{\prime \prime}-\mathrm{Fe}_{16} \mathrm{C}_{2}$. To discuss the differences between the mixing energies of supercells with different distributions of carbon, the carbon-carbon interaction energies are calculated. In the second part, the effect of 25 at.\% of Ni substitution on the lattice parameters of martensite is studied. The calculations of equilibrium lattice parameters and energies have been carried out using the Density Functional Theory (DFT).

\section{Calculation details}

The first-principles calculations are performed using the Projector Augmented Wave (PAW) [20] method as is implemented in the VASP code [21-22]. The calculations employ the Generalized Gradient Approximation (GGA) [23] for exchange-correlation energy. The calculations are done with the energy cutoff of $400 \mathrm{eV}$. k-points meshes are created by Monkhorst-Pack scheme [24]. 4x4x4 k-meshes are used for all cells with 128 atoms. The energy convergence criterion of the electronic self-consistency is chosen as $10^{-5} \mathrm{eV}$ for all calculations. The reciprocal space energy integration is performed by the Methfessel-Paxton [25] technique for structure relaxation. All calculations are performed within the spin polarized approximation.

\section{Results and discussion}

\section{III.1. Ordering of carbon atoms in $\mathrm{Fe}_{16} \mathrm{C}_{2}$}

To study the properties of $\mathrm{Fe}_{16} \mathrm{C}_{2}$ compound, the three types of long-range ordering are considered, corresponding to the following structures: (i) $\alpha-\mathrm{Fe}_{16} \mathrm{C}_{2}$ structure where carbon atoms are randomly distributed on the three octahedral sub-lattices, (ii) $\alpha^{\mathrm{Z}}-\mathrm{Fe}_{16} \mathrm{C}_{2}$ structure where carbon atoms are randomly distributed on one octahedral sub-lattice and (iii) $\alpha^{\prime \prime}-\mathrm{Fe}_{16} \mathrm{C}_{2}$ structure where carbon atoms are ordered and occupy specific sites on one octahedral sublattice. The unit-cells of these three structures are shown in Fig.1.

First, the total energies per iron atom for these three structures have been calculated. For the two structures $\alpha^{\mathrm{Z}}-\mathrm{Fe}_{16} \mathrm{C}_{2}$ and $\alpha-\mathrm{Fe}_{16} \mathrm{C}_{2}$, three SQS supercells (with $128 \mathrm{Fe}$ atoms $+16 \mathrm{C}$ atoms) have been considered with different carbon distributions on their respective interstitial sublattices. The results of these calculations are summarised in Table 1. Our results are in good agreement with those obtained from molecular dynamics calculations [19]. The ordered $\alpha^{\prime \prime}-$ $\mathrm{Fe}_{16} \mathrm{C}_{2}$ structure is the most stable one among the three considered structures. The partially ordered $\alpha^{\mathrm{Z}}-\mathrm{Fe}_{16} \mathrm{C}_{2}$ structure is the second most stable while the fully disordered $\alpha-\mathrm{Fe}_{16} \mathrm{C}_{2}$ is the least stable. The ordering energy from $\alpha$ to $\alpha^{\prime \prime}$ is $24.9 \mathrm{meV} / \mathrm{Fe}$ atom.

The relaxed $\alpha^{\prime \prime}-\mathrm{Fe}_{16} \mathrm{C}_{2}$ structure is perfectly tetragonal with a ratio $c / a=1.107$. The calculated lattice parameters using the PAW [20] potential and PBE [23] approximation for the exchange correlations function reproduce well the previous theoretical data obtained using the USPPGGA methods [19]. For the case of $\alpha^{\mathrm{Z}}-\mathrm{Fe}_{16} \mathrm{C}_{2}$ and $\alpha-\mathrm{Fe}_{16} \mathrm{C}_{2}$ structures, the average $c / a$ ratios are $1.10 \pm 0.01$ and $1.03 \pm 0.02$, respectively. The $c / a$ uncertainty is defined as the standard deviation of the three SQS supercells. Since, in $\alpha-\mathrm{Fe}_{16} \mathrm{C}_{2}$ structure the carbon atoms are randomly distributed in the three octahedral sub-lattices, the calculated tetragonality, as 
expected, is close to 1. On the other hand, the carbon distributions on one octahedral sub-lattice lead to a $c / a$ ratio of around 1.1 for both $\alpha^{Z}-\mathrm{Fe}_{16} \mathrm{C}_{2}$ and $\alpha^{\prime \prime}-\mathrm{Fe}_{16} \mathrm{C}_{2}$ structures.

a)

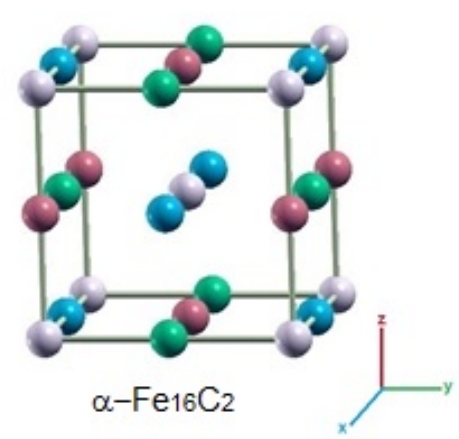

b)

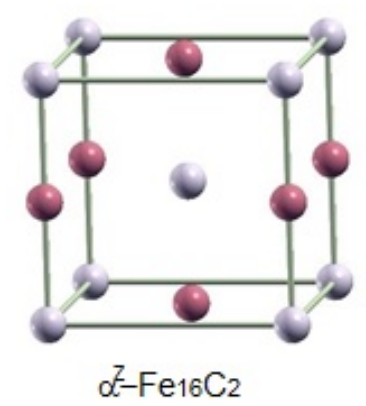

c)

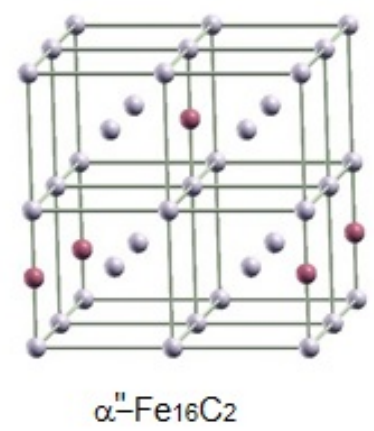

Figure 1. (a) The $\alpha-\mathrm{Fe}_{16} \mathrm{C}_{2}$ unit cell with the positions of carbon sites on the three $(x, y$ and $z)$ octahedral sub-lattices. (b) The $\alpha^{\mathrm{Z}}-\mathrm{Fe}_{16} \mathrm{C}_{2}$ unit cell. The carbon atoms occupy the $z$-octahedral interstitial sub-lattice, with a lattice parameter close to $a_{\mathrm{Fe}}$. (c) The $\alpha^{\prime \prime}-\mathrm{Fe}_{16} \mathrm{C}_{2}$ unit cell with the positions of carbon sites on the $z$-octahedral interstitial sub-lattice. The lattice parameter is close to $2 \mathrm{a}_{\mathrm{Fe}}$. Iron atoms are in grey, carbon sites are coloured in accordance to their sublattice (blue, green and red for $x, y$ and $z$ respectively).

Table 1. The equilibrium total energies per iron atom (meV/Fe atom), by taking as reference the energy of $\alpha-\mathrm{Fe}_{16} \mathrm{C}_{2}$, and lattice parameters of the $\alpha^{\prime \prime}-\mathrm{Fe}_{16} \mathrm{C}_{2}, \alpha^{\mathrm{Z}}-\mathrm{Fe}_{16} \mathrm{C}_{2}$ and $\alpha-\mathrm{Fe}_{16} \mathrm{C}_{2}$ structures from the $\mathrm{ab}$ initio calculations. The lattice parameters correspond to the unit cells constructed with $2 \times 2 \times 2$ bcc iron.

\begin{tabular}{c|c|c|c|c}
\hline \hline Property & $\alpha^{\prime \prime}-\mathrm{Fe}_{16} \mathrm{C}_{2}$ & $\alpha^{\prime \prime}-\mathrm{Fe}_{16} \mathrm{C}_{2}[19]$ & $\alpha^{\mathrm{Z}}-\mathrm{Fe}_{16} \mathrm{C}_{2}$ & $\alpha-\mathrm{Fe}_{16} \mathrm{C}_{2}$ \\
\hline Energy (meV/Fe atom) & -24.6 & $\mathrm{n} / \mathrm{a}$ & -9.9 & 0 \\
\hline Lattice parameter, $a(\AA)$ & 5.64 & 5.71 & $5.64 \pm 0.02$ & $5.77 \pm 0.05$ \\
\hline Lattice parameter, $c(\AA)$ & 6.25 & 6.31 & $6.22 \pm 0.04$ & $5.94 \pm 0.08$ \\
\hline Tetragonality, $c / a$ & 1.107 & 1.105 & $1.10 \pm 0.01$ & $1.03 \pm 0.02$ \\
\hline \hline
\end{tabular}

\section{III.2. Carbon-carbon interactions in martensite}

The carbon-carbon interactions have been calculated in order to discuss the differences between the mixing energies of supercells having different distributions of carbon atoms for a given concentration. In this section, the carbon-carbon interactions from the first nearest neighbours (pair length $\mathrm{a}_{\mathrm{Fe}} / 2$ ) to the nineteen nearest neighbours (pair length $2 \mathrm{a}_{\mathrm{Fe}}$ ) in the bcc-Fe are presented and discussed.

For designation, the first 19 positions of carbon octahedral sites as function of pair length are shown in Figure 2. 


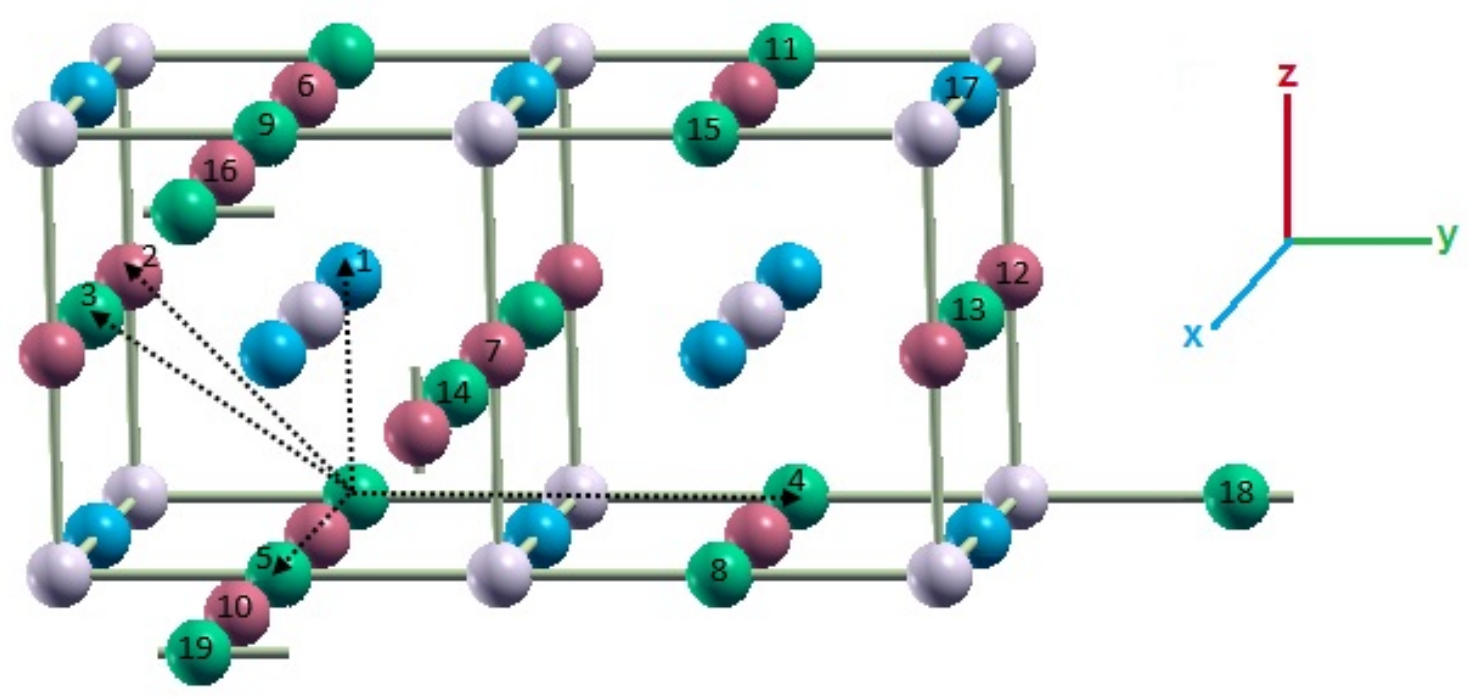

Figure 2. The first nineteen positions of the carbon octahedral interstitial sites. Iron atoms in grey, carbon sites coloured in accordance to their sub-lattice.

The carbon-carbon interaction energies calculated using supercells containing 128 atoms of iron and two atoms of carbon, are summarised in Table 2. Fig. 3 presents the comparison of our results with the theoretical results obtained by Domain et al. [26]. The interaction energy is defined as:

$$
V\left(A_{1}, A_{2}\right)=\left[E\left(A_{1}+A_{2}\right)+E_{r e f}\right]-\left[E\left(A_{1}\right)+E\left(A_{2}\right)\right]
$$

where $E\left(A_{1}+A_{2}\right), E_{\text {ref }}$ and $E\left(A_{i}\right)$ are the energies obtained when only atomic positions have been allowed to relax. $E\left(A_{1}+A_{2}\right)$ is the total energy of a supercell containing two carbon atoms. $E_{r e f}$ and $E\left(A_{i}\right)$ are the total energies of the supercells without carbon and with one carbon atom in the octahedral sub-lattice, respectively. With this definition, a positive interaction energy means repulsion while a negative interaction energy denotes attraction. All supercells have the same size, i.e. equivalent to the size of the relaxed supercell of bcc-iron. Note that $E\left(A_{1}\right)=E\left(A_{2}\right)$ for bcc lattice.

Our calculations (Table 2) show that most interactions are repulsive. They predict that the interactions become slightly attractive for configuration 19 (400) while the previous DFT results of Domain et al. [26] predict attractive interactions for configurations 6 (102), 8 (220) and 15 (222). Nevertheless, our results seem to be in agreement with the calculations of Ruban [27] and Hatcher et al. [28]. The DFT results by Ruban et al. [27] and Hatcher et al. [28] can be found in graphical form in the original papers. We suggest that the discrepancies in interaction energies are directly related to the size of cell used for calculations and the details of the electronic calculations. On the other hand, from Figure 3, it can be seen that the interactions are large at the first shells and decrease with distance with an exception of shells $4(020)$ and 18 (040) when one or two iron atoms are located along [010] direction between the two carbon atoms. Ruban [27] has found that strain-induced interactions become dominant just at the point where carbon atoms start attracting each other, i.e. from about the 14 (311) interaction. However, in our calculations we did not separate the chemical and elastic interactions. 
Table 2. The calculated carbon-carbon interaction energies (in $\mathrm{eV}$ ) at the same $\mathrm{V}(1-1)$ and different $\mathrm{V}(1-2)$ octahedral sub-lattices. The vectors of the nineteen neighbours as a function of pair length are correspondingly presented.

\begin{tabular}{c|c|c|c|c|c}
\hline \multicolumn{2}{l}{ Type of interaction } & $\begin{array}{c}\text { Distance of } \\
\text { separation } \\
\text { (units of } \mathrm{a}_{\mathrm{Fe}} \text { ) }\end{array}$ & Vectors & $\begin{array}{c}\text { This work-128 atoms } \\
\text { (PAW-PBE) }\end{array}$ & $\begin{array}{c}\text { Domain et al. [26] } \\
\text { (USPP-GGA) }\end{array}$ \\
\hline $\mathrm{V}(1-2)$ & 1 & $1 / 2$ & $1 / 2[001]$ & 1.9537 & 0.65 \\
\hline $\mathrm{V}(1-2)$ & 2 & $\sqrt{2} / 2$ & $1 / 2[011]$ & 0.8298 & 0.09 \\
\hline $\mathrm{V}(1-1)$ & 3 & $\sqrt{3} / 2$ & $1 / 2[111]$ & 0.2669 & 1.67 \\
\hline $\mathrm{V}(1-1)$ & 4 & 1 & $1 / 2[020]$ & 1.964 & 0.09 \\
\hline $\mathrm{V}(1-1)$ & 5 & 1 & $1 / 2[200]$ & 0.015 & -0.13 \\
\hline $\mathrm{V}(1-2)$ & 6 & $\sqrt{5} / 2$ & $1 / 2[102]$ & 0.046 & -0.14 \\
\hline $\mathrm{V}(1-2)$ & 7 & $\sqrt{6} / 2$ & $1 / 2[211]$ & 0.073 & \\
\hline $\mathrm{V}(1-1)$ & 8 & $\sqrt{2}$ & $1 / 2[220]$ & 0.0379 & \\
\hline $\mathrm{V}(1-1)$ & 9 & $\sqrt{2}$ & $1 / 2[202]$ & 0.1557 & \\
\hline $\mathrm{V}(1-2)$ & 10 & $3 / 2$ & $1 / 2[300]$ & 0.0645 & \\
\hline $\mathrm{V}(1-2)$ & 11 & $3 / 2$ & $1 / 2[122]$ & 0.1722 & \\
\hline $\mathrm{V}(1-2)$ & 12 & $\sqrt{10} / 2$ & $1 / 2[031]$ & 0.0712 & \\
\hline $\mathrm{V}(1-1)$ & 13 & $\sqrt{11} / 2$ & $1 / 2[131]$ & 0.3035 & \\
\hline $\mathrm{V}(1-1)$ & 14 & $\sqrt{11} / 2$ & $1 / 2[311]$ & 0.0154 & \\
\hline $\mathrm{V}(1-1)$ & 15 & $\sqrt{3}$ & $1 / 2[222]$ & 0.0306 & \\
\hline $\mathrm{V}(1-2)$ & 16 & $\sqrt{13} / 2$ & $1 / 2[302]$ & 0.0015 & \\
\hline $\mathrm{V}(1-2)$ & 17 & $\sqrt{14} / 2$ & $1 / 2[132]$ & 0.0055 & \\
\hline $\mathrm{V}(1-1)$ & 18 & 2 & $1 / 2[040]$ & 0.8286 & \\
\hline $\mathrm{V}(1-1)$ & 19 & 2 & $1 / 2[400]$ & -0.0161 & \\
\hline & & & & & \\
\hline
\end{tabular}

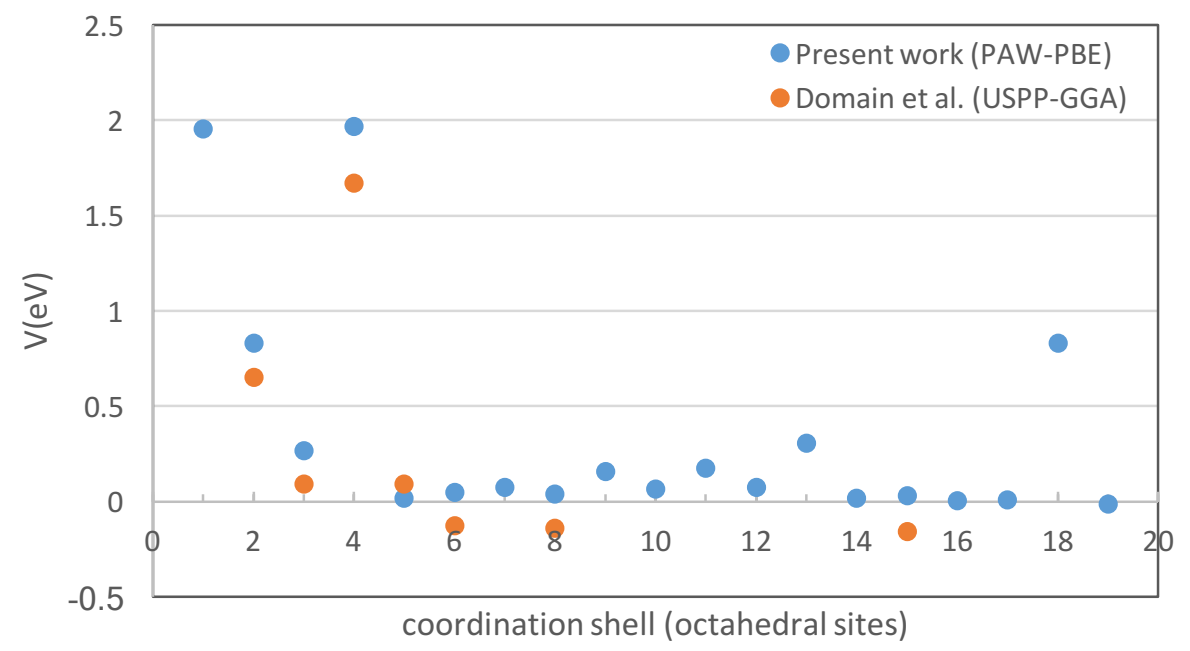


Figure 3. Calculated total carbon-carbon interaction energies in $(\mathrm{eV})$. The ab initio results of Domain et al. [26] are shown by red spheres.

\section{III.3. Effect of carbon concentration on the lattice parameter of $\mathrm{Fe}_{16} \mathrm{C}_{2 \mathrm{X}}$}

To study the structural properties of ferrous martensite, the carbon atoms are distributed randomly on a single octahedral sub-lattice with occupation of specific sites only: precisely those sites that correspond to carbon sites in the $\alpha^{\prime \prime}-\mathrm{Fe}_{16} \mathrm{C}_{2}$ stoichiometric structure with 12.5 at. $\%$ of carbon. Here the martensite is approximated by the phase $\mathrm{Fe}_{16} \mathrm{C}_{2 \mathrm{X}}$. The parameter $\mathrm{X}$ $(0<\mathrm{X}<1)$ is the occupancy factor of the carbon sublattice, i.e. the ratio of occupied interstitial sites by carbon atoms to the total number of interstitial sites in the interstitial sublattice of structure $\alpha^{\prime \prime}$. This gives us the possibility to treat the coherent spinodal decomposition between $\mathrm{Fe}(\mathrm{X}=0)$ and $\alpha^{\prime \prime}-\mathrm{Fe}_{16} \mathrm{C}_{2}(\mathrm{X}=1)$. The calculations have been performed with different supercells containing 128 iron atoms. Nine concentrations $\left(0 \leq \mathrm{x}_{\mathrm{c}} \leq 12.5\right.$ at.\%) are considered in total with $0,2,4,6,8,10,12,14$ and 16 interstitial atoms of carbon. For each concentration, three different supercells are used and an average of the structural parameters is calculated.

As described above, the $\alpha^{\prime \prime}-\mathrm{Fe}_{16} \mathrm{C}_{2}$ structure (with 16 carbon atoms and 128 iron atoms) is perfectly tetragonal. However, the structures with lower concentrations of carbon are slightly orthorhombic with very close lattice parameters $a$ and $b$. In these cases, the average $(a+b) / 2$ is calculated to represent the lattice parameter, noted $a_{F e C}$, for the considered carbon concentration.

In order to scale our results in the same way as the data of Cheng et al. [1] and the molecular dynamics results of Becquart et al.[29], the $\mathrm{c}_{\mathrm{FeC}} / \mathrm{a}_{\mathrm{Fe}}$ and $\mathrm{a}_{\mathrm{FeC}} / \mathrm{a}_{\mathrm{Fe}}$ ratios are presented in Figure 4. Our calculations have been done at $0 \mathrm{~K}$. In this case the lattice parameter of iron is $\mathrm{a}_{\mathrm{Fe}}=2.833$ $\AA$. It should be noted that both the experimental data of Cheng et al. and the MD results of Becquart et al. [29], given for comparison, are obtained at room temperature (300K). At this temperature, the lattice parameters of pure iron are $2.866 \AA$ and $2.855 \AA$, respectively. These values are slightly higher than the one obtained in the present work. It is well known that the ab initio calculations at $0 \mathrm{~K}$ underestimate the lattice parameter of bcc-iron. 


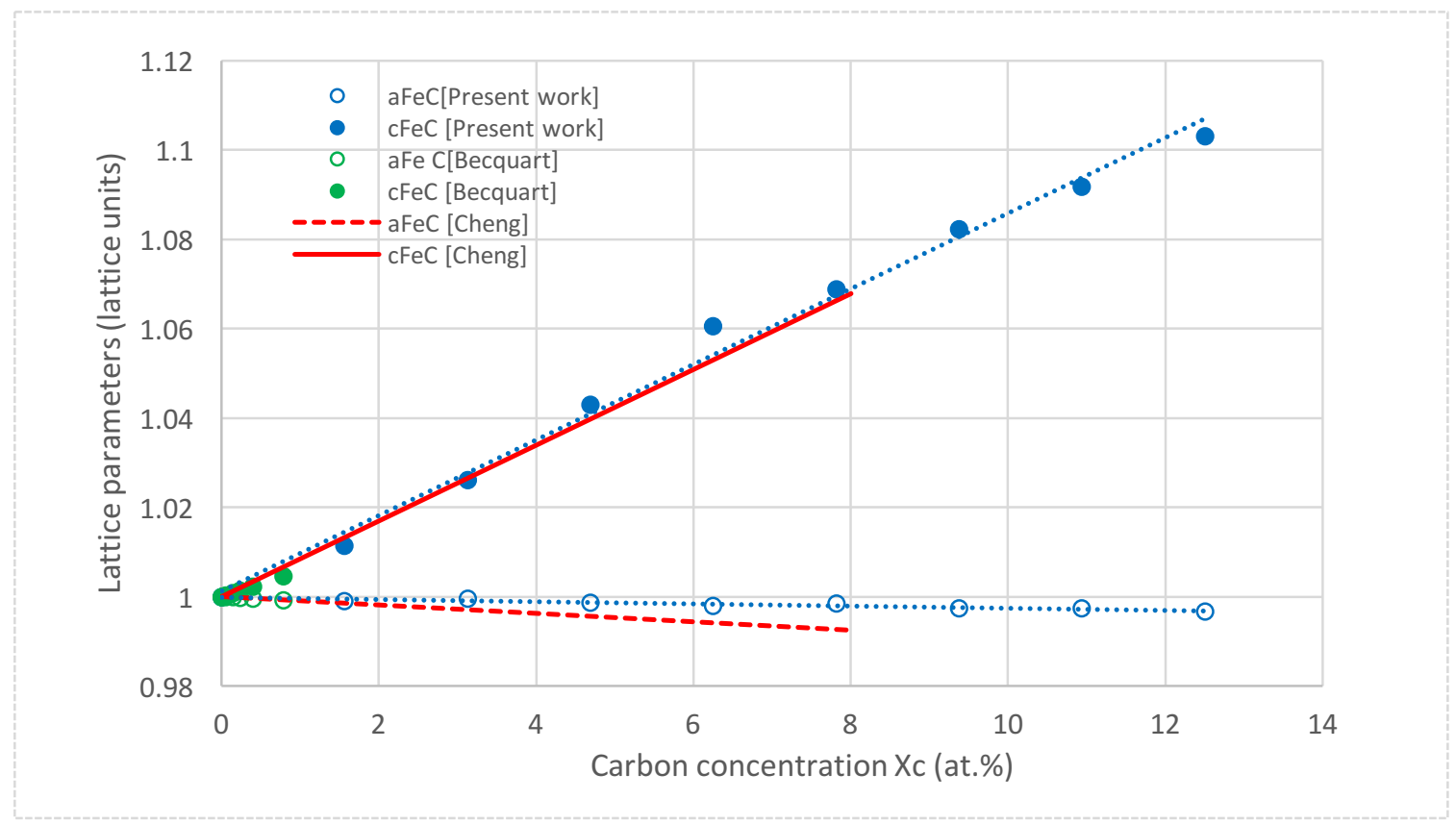

Figure 4. Lattice parameters of $\mathrm{Fe}_{16} \mathrm{C}_{2 \mathrm{X}}$ system (lattice units) as a function of carbon concentration. For comparison, the results of Cheng et al. [1] and Becquart et al. [29] are presented. The dotted lines correspond to the linear interpolations.

It can be seen in Fig. 4 that our calculations remarkably reproduce the linear dependence of lattice parameters with carbon content up to the high concentration of $\mathrm{x}_{\mathrm{C}}=12.5$ at $\%$ corresponding to $\mathrm{Fe}_{16} \mathrm{C}_{2}$. Quantitatively, our results are in good agreement with the $\mathrm{c}_{\mathrm{FeC}} / \mathrm{a}_{\mathrm{Fe}}$ ratio given by Cheng et al. [1] from the experimental data up to 8 at.\%. This indicates that our calculations reproduce the expansion of the lattice parameter $c$ of martensite as a function of carbon concentration. However, for the case of $\mathrm{a}_{\mathrm{FeC}} / \mathrm{a}_{\mathrm{Fe}}$, from about 2.5 at.\% of carbon our results diverge slightly, by $1 \%$, from both the experimental data and theoretical values of Becquart et al.[29].

\section{III.4. Mixing energies of $\mathrm{Fe}_{16} \mathrm{C}_{2 \mathrm{X}}$}

The mixing energies of different structures of $\mathrm{Fe}_{16} \mathrm{C}_{2 \mathrm{X}}$ system as function of carbon concentration are calculated with supercells containing 128 atoms of iron. The mixing energy per iron atom, as reference to pure iron and $\alpha^{\prime \prime}-\mathrm{Fe}_{16} \mathrm{C}_{2}$ stoichiometric structure, is defined as:

$$
\Delta E_{\text {mix }}=\left[E\left(F e_{128} C_{n}\right)-\frac{n}{16} E\left(F e_{128} C_{16}\right)-\left(1-\frac{n}{16}\right) E\left(F e_{128}\right)\right] / 128 \quad \text { Eq.5 }
$$

Where, $E\left(F_{128} C_{n}\right)$ is the total energy of a cell containing 128 atoms of iron and $n$ atoms of carbon $(\mathrm{n}=16 \mathrm{X}) . E\left(F_{128}\right)$ is the calculated total energy of bcc-iron and $E\left(F e_{128} C_{16}\right)$ is the total energy of the ordered $\alpha^{\prime \prime}-\mathrm{Fe}_{16} \mathrm{C}_{2}$ structure.

The calculated mixing energies at nine different concentrations $\left(0 \leq \mathrm{x}_{\mathrm{c}} \leq 12.5\right.$ at. $\left.\%\right)$ are presented in Figure 5. Similarly to the lattice parameters, for each concentration, calculations of $\Delta E_{\text {mix }}$ have been performed for three different SQS supercells with different carbon spatial distributions on the interstitial sub-lattice. For each concentration of carbon, the average of the three different mixing energies is also calculated and presented in Figure 5. Remembering that $\mathrm{X}=8 \mathrm{x}_{\mathrm{C}}$ is the occupancy factor of the $\alpha$ " interstitial sub-lattice $(0<\mathrm{X}<1)$, the average energy has been fitted according to the sub-regular solution model [36] in the form of a polynomial: 


$$
\Delta E_{m i x}=\omega_{F e C} X(1-X)^{2}
$$

with $\omega_{\mathrm{FeC}}=43 \mathrm{meV}$.

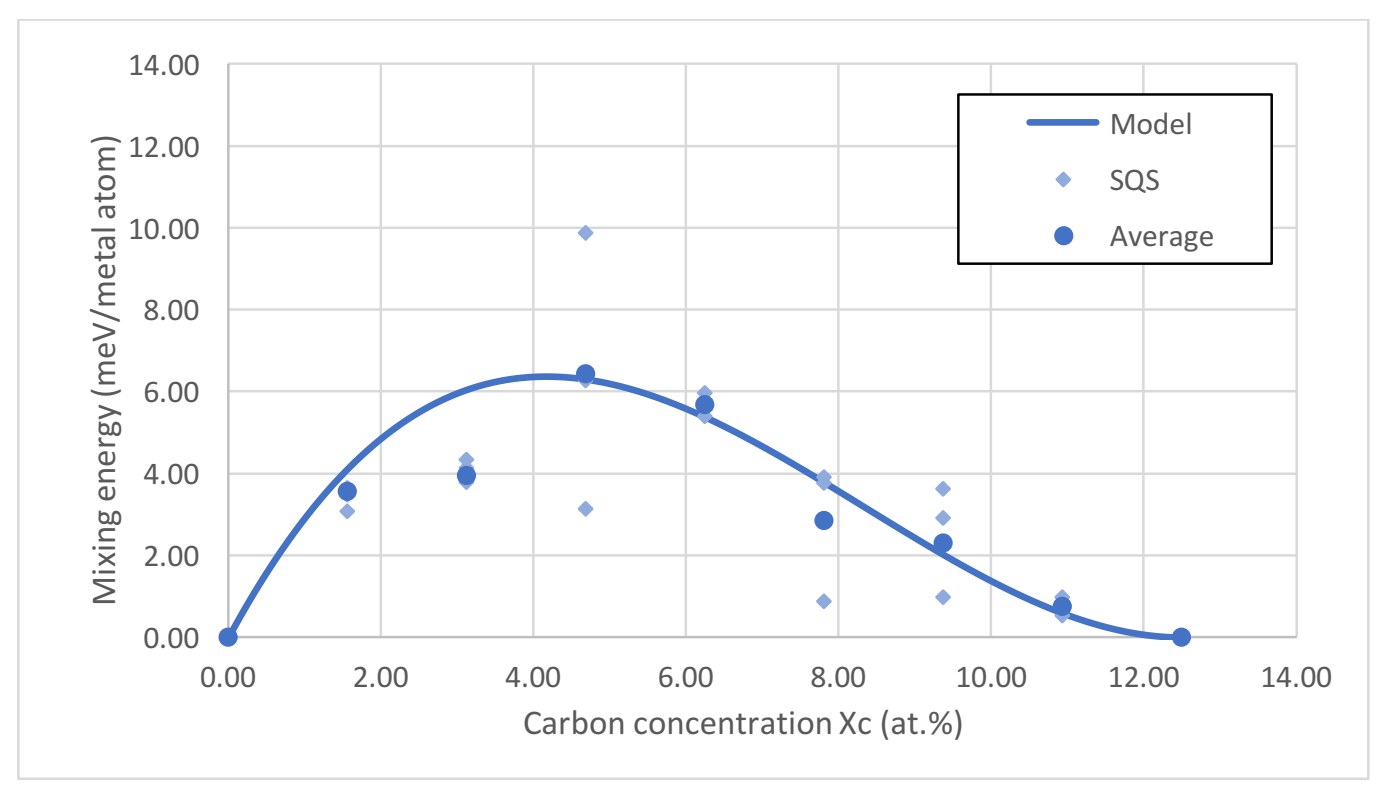

Figure 5. Mixing energy (in meV/Fe atom) of $\mathrm{Fe}_{16} \mathrm{C}_{2 \mathrm{X}}$ structures as a function of carbon concentration.

As can be seen in Figure 5, the mixing energies are positive for all carbon concentrations. The curve of the average $\Delta E_{m i x}$ is not symmetric around the medium concentration $x_{C}=6.25$ at.\% (i.e with 8 interstitial carbon atoms): it reaches a maximum for a carbon concentration around 4.7 at. $\%$ (i.e. with 6 interstitial carbon atoms).

Among the three different mixing energies for each concentration, some are grouped very close together and others are scattered. These differences are likely to be related to the carbon distributions in the interstitial sub-lattice and therefore to the carbon-carbon interactions. To clarify this point, we have chosen to analyse the carbon atom distribution in the three different SQS supercells for the carbon concentration of 4.68 at. \%. For this concentration, the differences between the mixing energies are significant (from 3.13 to $9.86 \mathrm{meV} / \mathrm{Fe}$ atom).

We have identified all carbon-carbon pairs in the three different SQS supercells. Table 3 summarises the number of different carbon-carbon pairs as a function of their lengths. The carbon-carbon interaction energies have been calculated for the first nearest (1NN) and second nearest neighbour $(2 \mathrm{NN})$ pairs in the $\alpha^{\prime \prime}-\mathrm{Fe}_{16} \mathrm{C}_{2}$ structure. The details of the calculations and the results of the interaction energies are presented and discussed in section III.2. In the case of the $\alpha^{\prime \prime}-\mathrm{Fe}_{16} \mathrm{C}_{2}$ structure, the $1 \mathrm{NN}$ and the $2 \mathrm{NN}$ correspond to the configurations 15 and 19 with lengths $\sqrt{3} \mathrm{a}_{\mathrm{Fe}}$ and $2 \mathrm{a}_{\mathrm{Fe}}$ respectively (see Figure 2).

The two values of the interaction energies for $1 \mathrm{NN}$ and $2 \mathrm{NN}$ carbon atoms are +0.025 and $0.028 \mathrm{eV}$, respectively. Therefore, the interactions are repulsive between the first nearest neighbours and attractive between $2 \mathrm{NN}$. Supercells ' 3 ' with the low mixing energy has eight $1 \mathrm{NN}$ pairs, while the two other supercells have nine $1 \mathrm{NN}$ pairs each. Thus, supercell ' 3 ' possesses the least number of repulsive interactions and this is why its mixing energy is lower 
than for the other supercells. Let's compare now the number of second nearest neighbours of supercells ' 1 ' and ' 2 '. Although they have the same number of $1 \mathrm{NN}$, the first supercell has six $2 \mathrm{NN}$ and the second has eight. Here, supercell ' 2 ' has additional attractive interaction energies between the $2 \mathrm{NN}$ than the supercell ' 1 '. Consequently, the mixing energy of supercell ' 2 ' is lower than that of structure ' 1 '. Note that, the number of $1 \mathrm{NN}$ and $2 \mathrm{NN}$ pairs is only one part of the explanation of the energy differences between the three SQS structures.

Table 3. Number and length of carbon-carbon pairs in the three $S Q S$ supercells of $\mathrm{Fe}_{128} \mathrm{C}_{6}$ (i.e with carbon concentration $\mathrm{x}_{\mathrm{c}}=4.68$ at.\%). The mixing energies are also given to identify the different supercells.

\begin{tabular}{c|l|l|l|l}
\hline Length & Supercell ' 1 ' & Supercell ' 2 ' & Supercell '3' \\
\hline & \multicolumn{3}{|c}{ Mixing energy (meV/Fe atom) } \\
\hline & +9.86 & +6.26 & +3.13 \\
\hline & \multicolumn{3}{|c}{ Number of C-C pairs in $\mathrm{Fe}_{128} \mathrm{C}_{6}$} \\
\hline$\sqrt{3} \mathrm{a}_{\mathrm{Fe}}$ & 9 & 9 & 8 \\
\hline $2 \mathrm{a}_{\mathrm{Fe}}$ & 6 & 8 & 6 \\
\hline
\end{tabular}

\section{III.5 Effect of carbon concentration on the lattice parameters of $(\mathrm{Fe}, \mathrm{Ni})_{16} \mathrm{C}_{2 \mathrm{X}}$}

In the following sections, we investigate the role of $\mathrm{Ni}$ substitution on the properties of $\mathrm{Fe}_{16} \mathrm{C}_{2 \mathrm{X}}$. As in the case of $\mathrm{Fe}_{16} \mathrm{C}_{2 \mathrm{X}}$, nine carbon concentrations are considered for the calculations of the lattice parameters of $(\mathrm{Fe}, \mathrm{Ni})_{16} \mathrm{C}_{2 \mathrm{X}}$. Calculations have been performed using disordered structures by considering simultaneously (i) the substitutional disorder of nickel atoms on the iron sub-lattice and (ii) the interstitial disorder of carbon atoms on the interstitial sub-lattice. Here also, the positions of interstitial carbon sites correspond to those of the $\alpha$ " $-\mathrm{Fe}_{16} \mathrm{C}_{2}$ structure.

In order to scale the lattice parameters of $(\mathrm{Fe}, \mathrm{Ni}){ }_{16} \mathrm{C}_{2 \mathrm{X}}$ systems to those of $\mathrm{Fe}_{16} \mathrm{C}_{2 \mathrm{X}}$, we have presented the $\mathrm{c}_{\mathrm{FeNiC}} / \mathrm{a}_{\mathrm{Fe}}$ and $\mathrm{a}_{\mathrm{FeNiC}} / \mathrm{a}_{\mathrm{Fe}}$ ratios in Figure 6 . Note that the resulting lattice parameter of carbon-free SQS-Fe25at.\%Ni structure for one bcc unit cell is $\mathrm{a}_{\mathrm{FeNi}}=2.854 \AA$ [30]. This lattice parameter is calculated using the same methods in the present study.

Figure 6 shows that the lattice parameters of $(\mathrm{Fe}, \mathrm{Ni}){ }_{16} \mathrm{C}_{2 \mathrm{X}}$ are linear functions of the carbon concentration. Additionally, the expansion and contraction of the lattice parameters are greater in $(\mathrm{Fe}, \mathrm{Ni}){ }_{16} \mathrm{C}_{2 \mathrm{X}}$ than in $\mathrm{Fe}_{16} \mathrm{C}_{2 \mathrm{X}}$. For example, at $x_{C}=12.5 \%$ the longitudinal deformations $\varepsilon=\left(c-a_{F e}\right) / a_{F e}$ induced by carbon insertion are $\varepsilon_{\mathrm{FeNiC}}=0.145$ and $\varepsilon_{\mathrm{FeC}}=0.106$. We show in the following that this behaviour can be explained in the frame of the elasticity theory of point defects. Indeed, the observed linear dependence of the lattice parameters $v s$ the carbon concentration can be written $a\left(x_{c}\right)=a_{0}\left(1+\delta_{a} x_{C}\right)$ and $c\left(x_{c}\right)=a_{0}\left(1+\delta_{c} x_{C}\right)$ where $\delta_{\mathrm{a}}$ and $\delta_{\mathrm{c}}$ are the lattice expansion concentration coefficients. The lattice parameter $a_{0}$ for carbon-free alloys being respectively $\mathrm{a}_{\mathrm{Fe}}$ and $\mathrm{a}_{\mathrm{FeNi}}$ for Ni-free and $25 \mathrm{at} . \% \mathrm{Ni}$ systems (see Table 4). For lattice parameter $c, 25$ at.\% addition of nickel results in an increase of carbon-induced deformation up to $37 \%: \varepsilon_{\mathrm{FeNiC}} / \varepsilon_{\mathrm{FeC}}=1.37$. This finding is in qualitative agreement with the DFT results of Al-Zoubi et al. [16]: the authors have found that 5 at. $\%$ of nickel enhances significantly the $c / a$ ratio of $\mathrm{Fe}_{16} \mathrm{C}_{1}$.

Table 4. Parameters used in the elasticity model of point defects. The elastic constants $\mathrm{C}_{\mathrm{ij}}$ 's and shear modulus $\mathrm{C}^{\prime}$ (in GPa) are extracted from [30]. 


\begin{tabular}{c|c|c|c|c|c|c}
\hline & $\mathrm{a}_{0}(\AA)$ & $\delta_{\mathrm{a}}$ & $\delta_{\mathrm{c}}$ & $\mathrm{C}_{11}$ & $\mathrm{C}_{12}$ & $\mathrm{C}^{\prime}$ \\
\hline bcc-Fe & 2.833 & -0.025 & 0.84 & 267 & 147 & 60 \\
\hline SQS-Fe25\%Ni & 2.854 & -0.25 & 1.07 & 186 & 132 & 27 \\
\hline
\end{tabular}

According to Bacon [32], Cochardt et al. [33] and Clouet et al. [34], the quadratic deformation induced by one carbon atom on a z-octahedral site in bcc lattice can be calculated from the dipole tensor $\mathrm{P}_{\mathrm{ij}}$ associated to the point defect. According to the tetragonal symmetry of the octahedral interstitial sites, the dipole tensor is diagonal and is characterized by only two components: $\mathrm{P}_{\mathrm{a}}$ and $\mathrm{P}_{\mathrm{c}}$ related respectively to the lateral and longitudinal deformations induced by the carbon atom. The components of the dipole tensor verify the following relations:

$$
\begin{gathered}
P_{a}=\frac{1}{2} a_{0}{ }^{3}\left[\left(C_{11}+C_{12}\right) \delta_{a}+C_{12} \delta_{c}\right] \\
P_{c}=\frac{1}{2} a_{0}{ }^{3}\left[2 C_{12} \delta_{a}+C_{11} \delta_{c}\right]
\end{gathered}
$$

where $\mathrm{C}_{\mathrm{ij}}$ are the elastic constants of the carbon-free matrix and $\delta_{\mathrm{a}, \mathrm{c}}$ are the lattice expansion concentration coefficients defined above. Applying these equations to bcc-Fe yields the values $P_{a}=8.03 \mathrm{eV}$ and $P_{c}=15.4 \mathrm{eV}$. On the other hand, for SQS structure Fe25at.\%Ni, $P_{a}=4.48 \mathrm{eV}$ and $P_{c}=9.65 \mathrm{eV}$. It is clear that both dipole components and elasticity constants are weaker in the case of $\mathrm{Ni}$ substitution. A rough estimate of the consequences on the longitudinal deformation can be derived as follows. From the inversion of Eq. 7 and 8 we obtain:

$$
\delta_{c}=\frac{2}{a_{0}^{3}} \frac{-2 C_{12} P_{a}+\left(C_{11}+C_{12}\right) P_{c}}{\left(C_{11}-C_{12}\right)\left(C_{11}+2 C_{12}\right)}
$$

Noting that the component $P_{a}$ has a minor influence on $\delta_{\mathrm{c}}$ compared to $P_{c}$, it appears that $\delta_{\mathrm{c}}$ scales approximately as the ratio $P_{c} / C^{\prime}$, where $\mathrm{C}^{\prime}=\left(\mathrm{C}_{11}-\mathrm{C}_{12}\right) / 2$ is the shear modulus. From Table 4, we have $\left(P_{c} / C^{\prime}\right)_{\mathrm{FeNiC}} /\left(P_{c} / C^{\prime}\right)_{\mathrm{FeC}}=1.39$, which is close to the value of 1.37 observed on $\varepsilon$. We conclude that the higher $c / a$ ratios in the nickel-bearing system is due the higher compliance of the latter due to nickel substitution.

Based on the results of neutron diffraction experiments [35], Kurdjumov et al. [31] have deduced that during the martensitic transformation of FeNiC system with high Ni content, all carbon atoms occupy the sites of a single octahedral sub-lattice and consequently induce the maximum tetragonality for a given carbon content. While, for the case of other freshly formed martensite i.e with low $\mathrm{Ni}$ content and $\mathrm{Ni}$-free, some of carbon atoms (about $20 \%$ ) are distributed on the two other octahedral sub-lattices. In our calculations of $\mathrm{Fe}_{16} \mathrm{C}_{2 \mathrm{x}}$ and $(\mathrm{Fe}, \mathrm{Ni}){ }_{16} \mathrm{C}_{2 \mathrm{X}}$ systems, $100 \%$ of the carbon atoms have been located on the z-octahedral lattice. Nonetheless, a high effect of nickel substitution on tetragonality is observed. We conclude that the influence of the nickel-induced softening on tetragonality cannot be discarded in this respect. 


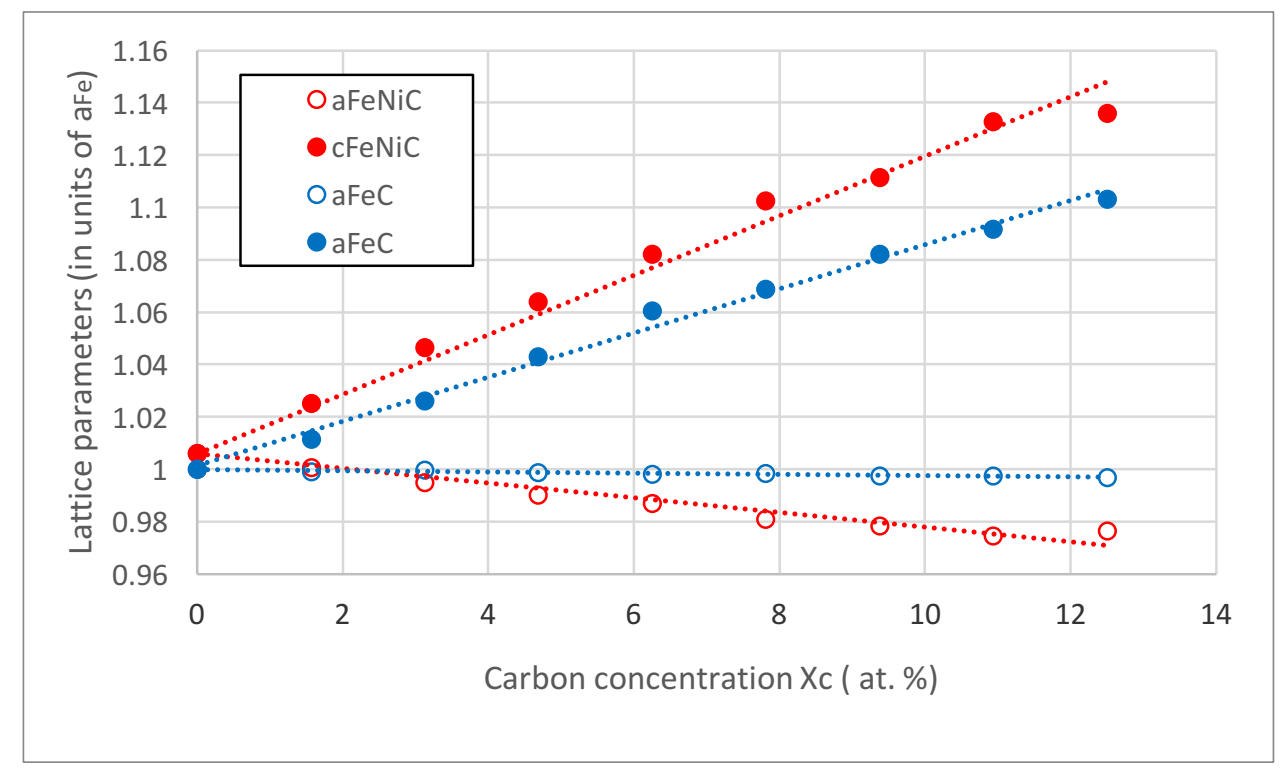

Figure 6. Lattice parameters of the $(\mathrm{Fe}, \mathrm{Ni}){ }_{16} \mathrm{C}_{2 \mathrm{X}}$ and $\mathrm{Fe}_{16} \mathrm{C}_{2 \mathrm{X}}$ systems (in units of $\mathrm{a}_{\mathrm{Fe}}$ ) as functions of carbon concentration.

\section{III.6. Mixing energies of $(\mathrm{Fe}, \mathrm{Ni})_{16} \mathrm{C}_{2 \mathrm{X}}$}

The mixing energies of different $(\mathrm{Fe}, \mathrm{Ni}){ }_{16} \mathrm{C}_{2 \mathrm{X}}$ structures as function of carbon concentration have been calculated with supercells containing 128 metallic atoms (with $96 \mathrm{Fe}+32$ substitutional $\mathrm{Ni}$ ). In these calculations, the mixing energy per atom was calculated using the following expression:

$$
\Delta E_{\text {mix }}=\left[E\left(F e_{96} N i_{32} C_{n}\right)-\frac{n}{16} E\left(F e_{96} N i_{32} C_{16}\right)-\left(1-\frac{n}{16}\right) E\left(F e_{96} N i_{32}\right)\right] / 128 \quad \text { Eq.10 }
$$

where, $E\left(\mathrm{Fe}_{96} \mathrm{Ni}_{32} \mathrm{C}_{n}\right)$ is the total energy of a cell containing 96 atoms of iron, 32 substitutional atoms of nickel and $n$ interstitial atoms of carbon, and $E\left(\mathrm{Fe}_{96} \mathrm{Ni}_{32}\right)$ is the total energy of the SQS-Fe25at.\%Ni structure. $E\left(\mathrm{Fe}_{96} \mathrm{Ni}_{32} \mathrm{C}_{16}\right)$ is the total energy average of two structures with disorder on the substitutional lattice only, the interstitial carbon sublattice being totally filled.

The calculated mixing energies for nine different concentrations are presented in Figure 7. Similarly to the case of lattice parameters, for each concentration, two different SQS$(\mathrm{Fe}, \mathrm{Ni})_{16} \mathrm{C}_{2 \mathrm{X}}$ supercells, with different substitutional nickel and interstitial carbon distributions, have been taken into account for the calculations of $\Delta E_{m i x}$. Additionally, for each carbon concentration, the average of the two different mixing energies is calculated and presented in Figure 7. The average energy of mixing is fitted with an equation of type Eq. 6 with $\omega_{\mathrm{FeNiC}}=$ $75 \mathrm{meV}$.

As shown in Figure 7, all average mixing energies are positive. Similarly to the $\mathrm{Fe}_{16} \mathrm{C}_{2 \mathrm{X}}$ system, the curve of the average $\Delta E_{\text {mix }}$ is not symmetric around the medium concentration $x_{C}=6.25$ at. $\%$ : the maximum corresponds to a concentration around $x_{C}=4.7$ at. \% (i.e with 6 interstitial carbon atoms). Moreover, the highest mixing energy value for the $(\mathrm{Fe}, \mathrm{Ni}){ }_{16} \mathrm{C}_{2 \mathrm{X}}$ system $(\sim 11$ $\mathrm{meV} / \mathrm{metal}$ atom) is greater than the one of the $\mathrm{Fe}_{16} \mathrm{C}_{2 \mathrm{X}}$ system $(\sim 6 \mathrm{meV} / \mathrm{Fe}$ atom). This indicates that unmixing of martensite by spinodal decomposition is favoured by the nickel substitution. 


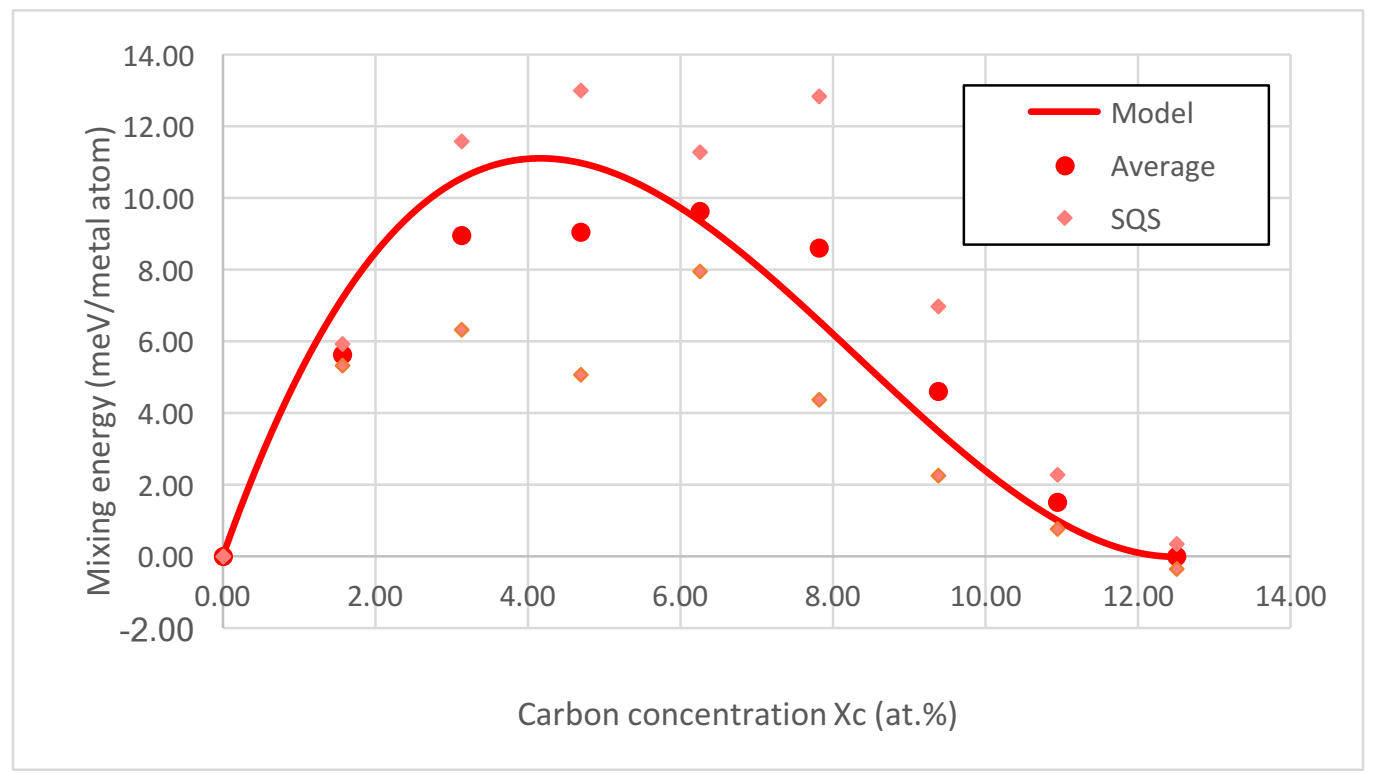

Figure 7. Mixing energies (in meV/ metal atom) of (Fe,Ni) ${ }_{16} \mathrm{C}_{2 \mathrm{X}}$ structures as a function of carbon concentration.

In order to quantify the influence of $25 \mathrm{at} . \% \mathrm{Ni}$ substitution on the driving force for unmixing, the free energy of mixing $\Delta \mathrm{F}_{\text {mix }}=\Delta \mathrm{E}_{\text {mix }}-\mathrm{T} \Delta \mathrm{S}_{\text {mix }}$ is calculated. Under the hypothesis of random distribution of the carbon atoms on the interstitial sites of $\alpha$ ' $-\mathrm{Fe}_{16} \mathrm{C}_{2}$, the entropy of mixing per metal atom writes

$$
\Delta S_{\text {mix }}=-\frac{1}{8} k_{B}[X \ln X+(1-X) \ln (1-X)],
$$

where $\mathrm{X}$ is the occupancy factor of the interstitial sublattice, as defined above. The free energies of mixing for both systems are presented in Figure 8 . The temperature $\mathrm{T}=300 \mathrm{~K}$ has been chosen for the purpose of illustration.

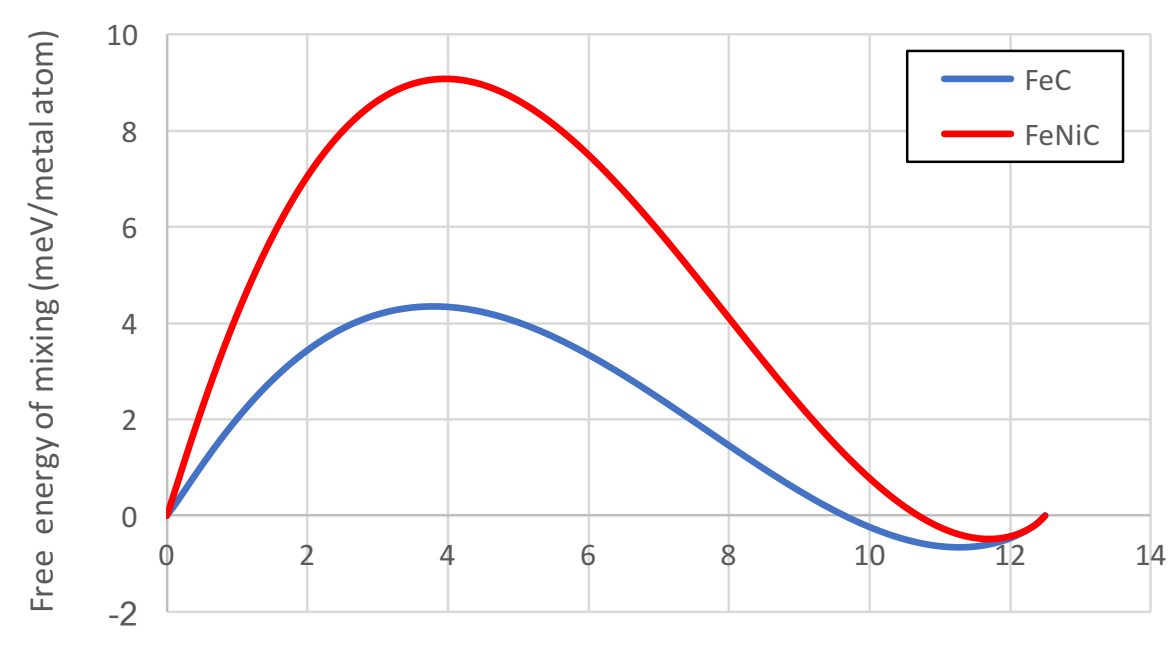

Carbon concentration Xc (at.\%)

Figure 8. Free energies of mixing (in meV/metal atom) for $\mathrm{Fe}_{16} \mathrm{C}_{2 \mathrm{X}}$ and $(\mathrm{Fe}, \mathrm{Ni}){ }_{16} \mathrm{C}_{2 \mathrm{X}}$ systems as a function of carbon concentration. 
The vanishing slopes of $\Delta \mathrm{E}_{\text {mix }}$ functions in the vicinity of the stoichiometric compound $\mathrm{Fe}_{16} \mathrm{C}_{2}$ (i.e. for $x_{C}$ close to 12.5 at $\%$ ) (Figures 6 and 7) result in minimal and negative values of $\Delta \mathrm{F}_{\text {mix }}$ in this region. From the common tangent construction, a two-phase equilibrium appears at $\mathrm{T}=300 \mathrm{~K}$ between a very dilute phase $\left(x_{C} \approx 0\right)$ and an under-stoichiometric phase $\left(x_{C}<12.5 \%\right)$, for both systems. In addition, from the shape of the curves, it can be concluded that the driving force for unmixing of martensite is higher with $25 \% \mathrm{Ni}$ alloying than without.

\section{Conclusion}

Using first-principles calculations based on the PAW potential and PBE approximation for the exchange correlation, the effect of carbon distribution and nickel substitution on the $(\mathrm{Fe}, \mathrm{Ni}){ }_{16} \mathrm{C}_{2 \mathrm{X}}$ system has been investigated. Three structures have been studied: $\alpha^{\prime \prime}-\mathrm{Fe}_{16} \mathrm{C}_{2}, \alpha^{\mathrm{Z}}-$ $\mathrm{Fe}_{16} \mathrm{C}_{2}$ and $\alpha-\mathrm{Fe}_{16} \mathrm{C}_{2}$. Our results show that the stoichiometric ordered $\alpha^{\prime \prime}$ structure is the most stable among the three. The lattice parameters of both $\mathrm{Fe}_{16} \mathrm{C}_{2 \mathrm{X}}$ and $(\mathrm{Fe}, \mathrm{Ni})_{16} \mathrm{C}_{2 \mathrm{X}}$ systems vary linearly with carbon concentration, up to the high value of $x_{C}=12.5$ at.\%. We find that nickel substitution enhances the expansion of parameter $c$ of the $\mathrm{Fe}_{16} \mathrm{C}_{2 \mathrm{X}}$ system by $37 \%$. This is related to the fact that the disordered Fe25at.\%Ni alloy is more compliant than pure bcc-iron. The mixing energies of $\mathrm{Fe}_{16} \mathrm{C}_{2 \mathrm{X}}$ and the $(\mathrm{Fe}, \mathrm{Ni}){ }_{16} \mathrm{C}_{2 \mathrm{X}}$ systems are positive for all carbon concentrations. The highest mixing energy value for (Fe,Ni) ${ }_{16} \mathrm{C}_{2 \mathrm{X}}(\sim 11 \mathrm{meV} / \mathrm{metal}$ atom) is greater than that of $\mathrm{Fe}_{16} \mathrm{C}_{2 \mathrm{X}}(\sim 6 \mathrm{meV} / \mathrm{Fe}$ atom $)$. This indicates that unmixing of martensite by spinodal decomposition is favoured by nickel substitution. It also suggests that the higher Zener ordering observed in nickel-bearing iron alloys is due to the softening effect of nickel substitution.

\section{Acknowledgments}

This study has been performed in the framework of the ANR-13-BS08-0014 SPIDERMAN project funded by the Agence Nationale de la Recherche (ANR). The calculations were carried out partially on the mesocentre of the Aix-Marseille University (project No. 16b045), and partially on the clusters of IDRIS (project No. 100524).

\section{References}

[1] L. Cheng, A. Bottger, Th.H. de Keijser and E. Mittemeijer, Scripta Metal. et Mater. 24, 509 (1990).

[2] P.G. Winchell, Sc.D. thesis, MIT, Cambridge, MA, 1958.

[3] L. Xiao, Z. Fan, Z. Jinxiu, Z. Mingxing, K. Mohuang, and G. Zhenqi, Phys. Rev. B 52, 9970 (1995).

[4] Z. Fan, L. Xiao, Z. Jinxiu, K. Mokuang, and G. Zhenqi, Phys. Rev. B 52, 9979 (1995).

[5] M. Watanabo and C.M. Wayman, Scr, Metall. 5, 109 (1972).

[6] L.I. Lyssak and Ja. N. Vovk, Fiz. Met. Metalloved. 20,540 (1965).

[7] C. Zener, Phys. Rev. 74, 639 (1948).

[8] G. Khachaturyan, Theory of structural transformation in solids (Wiley, New York, 1983).

[9] A. Udyansky, J. von Pezold, V. N. Bugaev, M. Friak and J. Neugebauer, Phys. Rev. B 79, $224112(2009)$. 
[10] L.I. Lyssak and Ja. N. Vovck, Fiz. Met. Metalloved. 31, 646 (1971).

[11] L.I. Lyssak and Ja. N. Vovck and Ju. M. Polishchuk, Fiz. Met. Metalloved. 23, 898 (1967).

[12] L.I. Lyssak and L.O. Andrushchik, Fiz. Met. Metalloved. 28, 348 (1969).

[13] F.E. Fujita, Metall. Trans. A 8, 1727 (1977).

[14] L.I. Lyssak, Fiz. Met. Metalloved. 45, 1230 (1978).

[15] G. Kurdjumov, Metall. Trans. A 7, 999 (1976).

[16] N. Al-Zoubi, N.V. Skorodumova, A. Medvedeva, J. Anderson, G. Nilson, B. Johansson and L. Vitos, Phys. Rev. B 85 , 014112 (2012).

[17] K.A. Taylor, L. Chang, G.B. Olson, G.D. W Smith, M. Cohen and J.B.V Sand, Metall. Trans. 20 A, 2717 (1989).

[18] G.B. Olson and W. S. Owen, Martensite. A Tribute to Moriss Cohen (ASM International, Metals Park, Ohio, 1992).

[19] C. W. Sinclair, M. Perez, R.G.A. Veiga and A. Weck, Phys. Rev. B 81 (2010).

[20] G. Kresse and D. Joubert, Phys. Rev. B 59, 1758 (1999).

[21] G. Kresse and J. Furthmuller, Comput. Mater. Sci. 6, 15 (1996).

[22] G. Kresse and J. Furthmuller, Phys. Rev. B 54, 11169 (1996).

[23] J.P. Rerdew, K. Burke, and M. Ernzerhof, Phys. Rev. lett. 77, 3865 (1996).

[24] H. J. Monkhorst and J.D. Pack, Phys. Rev. B 13, 5188 (1976).

[25] M. Methfessel and A.T. Paxton, Phys. Rev. B 40, 3616 (1989).

[26] C. Domain, C.S Becquard, and J. Foct, Phys. Rev. B 69, 144112 (2004).

[27] A.V. Ruban, Phys. Rev B 90, 144106 (2014).

[28] N. Hatcher, G. K. H. Madsen and R. Drautz, Phys. Rev. B 86, 155115 (2012).

[29] C.S. Becquart, J.M. Raulot, G. Bencteux, C. Domain, M. Perez, S. Garruchet, H. Nguen, Comput. Mater. Sci. 40, 119 (2007).

[30] S. Chentouf, P. Maugis, Comput. Mater. Sci., 126, 82 (2017).

[31] G. V. Kurdjumov and A.G. Khachaturyan, Acta. Mattaurgica, 23, 1077 (1975).

[32] D. J. Bacon, Scripta Metallurgica, 3, 735-740 (1969).

[33] A.W. Cochardt, G. Schoeck and H. Wiedersich, Acta Met. 3, 533 (1955).

[34] E. Clouet, S. Garruchet, H. Nguyen, Michel Perez, C. Becquart, Acta Materialia, 56, 3450 (2008).

[35] I.R. Entin, V.A. Somenkov and S. SH. Shilstein, Dokl. Akab. Nauk USSR 206, 1096 (1972).

[36] H.K. Hardy, Acta Metallurgica, 1, 202 (1953). 